03,13

\title{
Электронная структура ультратонкой пленки окисла молибдена
}

\author{
() П.А. Дементьев ${ }^{1}$, Е.В. Иванова ${ }^{1}$, М.Н. Лапушкин ${ }^{1}$, Д.А. Смирнов ${ }^{2}$, С.Н. Тимошнев ${ }^{3}$ \\ ${ }^{1}$ Физико-технический институт им. А.Ф. Иофрфе РАН, \\ Санкт-Петербург, Россия \\ ${ }^{2}$ Institut für Festkörper- und Materialphysik, Technische Universität \\ Dresden, 01062 Dresden, Germany \\ ${ }^{3}$ Санкт-Петербургский национальный исследовательский Академический университет им. Ж.И. Алферова РАН, \\ Санкт-Петербург, Россия \\ E-mail: lapushkin@ms.ioffe.ru
}

Поступила в Редакцию 4 июня 2020 г.

В окончательной редакции 4 июня 2020 г.

Принята к публикации 4 июня 2020 г.

\begin{abstract}
Проведены исследования методом фотоэлектронной спектроскопии в сверхвысоком вакууме электронной структуры ультратонкой пленки окисла молибдена, полученной при окислении молибдена при давлении кислорода 1 Torr, и влияния адсорбции атомов натрия Na на его электронную структуру. Изучены спектры фотоэмиссии из валентной зоны и остовных уровней $\mathrm{O} 2 s$, Мо $3 d$, Мо $3 p$ и Na $2 p$ при синхротронном возбуждении в диапазоне энергий фотонов 80-600 eV. Показано, что в сформированной пленке окисла молибден находится в двух состояниях: $\mathrm{Mo}^{6+}$ и $\mathrm{Mo}^{4+}$. На поверхности окисла кислород находится как в составе окислов, так и в гидроксиле. Показано, что на поверхности образуется $\mathrm{MoO}_{3}$, а на удалении от поверхности $\mathrm{MoO}_{2}$. Напыление атомов Na приводит к интеркаляции слоя окисла молибдена.
\end{abstract}

Ключевые слова: окислы молибдена, фотоэмиссия, натрий, интеркаляция.

DOI: 10.21883/FTT.2020.10.49906.121

\section{1. Введение}

Окислы переходных металлов и, в частности, окислы молибдена не только являются предметом научных исследований, но и имеют широкое применение при создании различных сенсоров, датчиков, тонкопленочных транзисторов, солнечных элементов, „умных“ окон, накопителей энергии, биосенсоров, катализаторов, фотои электрохромных материалов, эмиттеров для поверхностной ионизации в масс-спектроскопии и т.д. Одним из перспективных направлений использования окислов молибдена является создание накопителей энергии, при этом речь идет не только о разработке литий-ионных батарей и суперконденсаторов, но и об использовании других щелочных металлов вместо лития: натрия или калия, что может привести к резкому удешевлению устройств. Наиболее перспективным является создание натрий-ионных батарей на основе $\mathrm{MoO}_{3}$ и $\mathrm{MoO}_{2}$ [1-7]. Также следует отметить, что направление исследований нацелено на изучение морфологических и электрохимических характеристик систем натрий-окисел молибдена, а изменение электронной структуры окислов при интеркаляции ее натрием мало изучено.

Существует большое количество окислов молибдена разной стехиометрии и структуры. Наибольший интерес как с точки зрения исследований, так и с точки зрения применения представляет $\mathrm{MoO}_{3}$. Известно несколько фаз $\mathrm{MoO}_{3}$ : термодинамически стабильная орторомбическая $\alpha$-фаза, метастабильная моноклинная $\beta$-фаза и метастабильная гексагональная $h$-фаза. $\alpha-\mathrm{MoO}_{3}$ фаза имеет слоистую структуру, состоящую из двухслойных слоев октаэдра $\mathrm{MoO}_{6}$, связанных между слоями силами Ван-дер-Ваальса [8] со следующими параметрами решетки: $a=0.396 \mathrm{~nm}, b=1.386 \mathrm{~nm}$ и $c=0.376 \mathrm{~nm}$. Было показано, что такая структура позволяет проникать ионам натрия между слоев октаэдров, т.е. происходит интеркаляция окисла молибдена атомами натрия [9]. Ширина запрещенной зоны этой фазы составляет около $3.0 \mathrm{eV}$. Расчеты показывают, что валентная зона $\mathrm{MoO}_{3}$ сформирована из состояний $\mathrm{O} 2 p$ с незначительной примесью Мо $4 d$ состояний. [8,10-13]. Электронная структура окисла молибдена хорошо изучена для образцов, полученных различными способами. Было обнаружено, что спектр валентной зоны, так же как и форма спектров остовных уровней молибдена зависят как от внешних условий, так и методов приготовления [13-16].

Второй по популярности, но не менее важный для практического применения окисел $\mathrm{MoO}_{2}$ также имеет несколько фаз, но наибольший интерес представляет лишь $\beta$-моноклинная фаза, имеющая структуру рутила с цепочками октаэдров $\mathrm{MoO}_{6}$, которые расположены на оси „,c кристаллической ячейки. Обнаружено, что такая структура позволяет ионам лития проникать вглубь окисла [17]. В зависимости от условий создания окисла и проведения экспериментов $\mathrm{MoO}_{2}$ может быть металлом, полуметаллом или изолятором. Например, в $[8,18]$ показано, что $\mathrm{MoO}_{2}$ является металлом. Однако в исследовании [19] показано, что $\beta-\mathrm{MoO}_{2}$ имеет широкую запрещенную зону $\sim 2.7 \mathrm{eV}$, причем ширина запрещенной зоны зависит от парциального давления кислорода при получении окисла. В [20] для тетрагональной фазы $\mathrm{MoO}_{2}$ из оптических измерений получено значение ши- 
рины запрещенной зоны $2.39 \mathrm{eV}$, а из фотоэмиссионных измерений получено, что максимум валентной зоны расположен на $1.98 \mathrm{eV}$ ниже уровня Ферми. Тем не менее, дискуссия на эту тему находится за рамками данной статьи.

Существуют различные методы получения пленок окислов молибдена: это испарение различными способами окислов молибдена в вакууме, жидкофазные способы, электрохимический синтез, и т.д. [21]. Одним из простых и дешевых методов получения тонких пленок окисла молибдена является прогрев молибдена в атмосфере кислорода при различных давлениях последнего. При исследованиях термически окисленных пленок молибдена основное внимание уделяется изучению морфологии поверхности, электрохимическим, оптическим и электронным свойствам пленок и т.д. По форме спектров остовных уровней Мо $3 d$ или Мо $4 d$ можно определить, в каком состоянии находится молибден $-\mathrm{Mo}^{4+}, \mathrm{Mo}^{5+}$ или $\mathrm{Mo}^{6+}$. Объектами исследований являются напыленные пленки молибдена или молибденовая фольга. Так, в [22] была исследована пленка окисла молибдена, полученная при окислении молибденовой фольги при температуре $T=250^{\circ} \mathrm{C}$ в течение $4 \mathrm{~h}$, и показано, что получается пленка $\mathrm{MoO}_{3}$, процесс восстановления водородом которой был также изучен. В [23] исследованы пленки молибдена, полученные при магнетронном распылении и окисленные на воздухе в течение $3 \mathrm{~h}$ в диапазоне температур 473-673 К. Пленки имели толщину 920-980 nm. Термическое окисление пленок молибдена при $T=573 \mathrm{~K}$ приводит к образованию окисла, состоящего из смеси $\alpha$ - и $\beta-\mathrm{MoO}_{3}$-фаз, с преобладанием фазы $\alpha-\mathrm{MoO}_{3}$, а при $T=673 \mathrm{~K}$ образуется только $\alpha-\mathrm{MoO}_{3}$-фаза. В [24] исследовано окисление молибдена, полученного при магнетронном распылении молибдена, при $T=473 \mathrm{~K}$ в диапазоне давлений кислорода от $10^{-6}$ до $10^{5} \mathrm{~Pa}$ в течение $10 \mathrm{~min}$. Показано, что при давлении $10^{-6} \mathrm{~Pa}$ получается окисел $\mathrm{MoO}$, увеличение давления кислорода до $10^{-4} \mathrm{~Pa}$ при окислении приводит к формированию смеси окислов $\mathrm{MoO}, \mathrm{MoO}_{2}$ и $\mathrm{MoO}_{3}$, а окисление при $10^{5} \mathrm{~Pa} \mathrm{приводит} \mathrm{к} \mathrm{формированию} \mathrm{окисла} \mathrm{MoO}_{3}$ с небольшой примесью $\mathrm{Mo}_{2} \mathrm{O}_{5}$. В [25] показано, что окисление напыленных пленок молибдена в атмосфере кислорода при температуре $673 \mathrm{~K}$ происходит частичное окисление с регистрацией двух окислов: $\mathrm{MoO}_{2}$ и $\mathrm{MoO}_{3}$, с преобладанием последнего в спектре. Увеличение температуры окисления до $873 \mathrm{~K}$ приводит к формированию только $\mathrm{MoO}_{3}$. Дальнейшее увеличение температуры окисления до $973 \mathrm{~K}$ приводит к увеличению доли окислов с меньшей степенью окисления. В [26] исследовано окисление молибденовой фольги в кислороде при $T=673 \mathrm{~K}$ в течение $1 \mathrm{~h}$, которое приводит к формированию аморфной пленки окисла $\mathrm{MoO}_{3}$ толщиной более $11 \mathrm{~nm}$, а при окислении в течение $1 \mathrm{~h}$ при $T=473 \mathrm{~K}$ в спектре Мо $3 d$ выделены состояния $\mathrm{Mo}^{4+}, \mathrm{Mo}^{5+}$ с преобладающим вкладом $\mathrm{Mo}^{6+}$. В [27] исследовано окисление молибденовой фольги при давлении $6.5 \cdot 10^{-4} \mathrm{~Pa}$ в зависимости от дозы кислорода в Ленгмюрах $(\mathrm{L})$. При комнатной температуре экспозиция в кислороде $5000 \mathrm{~L}$ не приводит к изменениям в спектре Мо $3 d$. Бомбардировка при комнатной температуре ионами кислорода с энергией $500 \mathrm{eV}$ с дозами O $4.75 \cdot 10^{15} \mathrm{at} / \mathrm{cm}^{2}$ и $1.5 \cdot 10^{16} \mathrm{at} . / \mathrm{cm}^{2}$ приводит к формированию окислов $\mathrm{MoO}_{2}, \mathrm{Mo}_{2} \mathrm{O}_{5}$ и $\mathrm{MoO}_{3}$. Основное состояние окисла молибдена $-\mathrm{Mo}^{6+}$. В [28] с помощью фотоэлектронного спектрометра низкого давления исследовано термическое окисление молибдена при давлении кислорода 1 mbar и $T=700 \mathrm{~K}$ и показано, что происходит постепенное окисление от $\mathrm{MoO}_{2}$ к $\mathrm{Mo}_{2} \mathrm{O}_{5}$ и затем к пленке окисла молибдена $\mathrm{MoO}_{3}$, которая полностью формируется за $16 \mathrm{~h}$, что было четко показано по изменению спектров валентной зоны и остовного уровня Мо $3 d$. На промежуточных стадиях наблюдались все типы окислов $\left(\mathrm{MoO}_{2}, \mathrm{Mo}_{2} \mathrm{O}_{5}\right.$ и $\mathrm{MoO}_{3}$ ) с постепенным увеличением доли $\mathrm{MoO}_{3}$. Использовалась энергия возбуждения фотоэмиссии $21.8 \mathrm{eV}$, что, по мнению авторов, позволяло исследовать приповерхностную область толщиной $1-2 \mathrm{~nm}$. С учетом данных, полученных при энергии возбуждения $h v=1486.6 \mathrm{eV}$ с глубиной зондирования 8-9 nm, они предположили, что на поверхности образуется $\mathrm{MoO}_{3}$ с последующим формированием слоя $\mathrm{MoO}_{2}$ на металлическом молибдене. Ранее [29] мы исследовали окисление молибденовой фольги на воздухе при температуре $1000 \mathrm{~K}$ в течение 1 min. Было показано, что спектр валентной зоны имеет вид, характерный для $\mathrm{MoO}_{3}$.

В настоящей работе была поставлена задача исследования электронной структуры молибденовой фольги, окисленной при давлении 1 Torr, а также влияние напыления атомов натрия на электронную структуру пленки окисла молибдена, что является важным для изучения процесса интеркаляции окислов металлов щелочными металлами.

\section{2. Эксперимент}

Молибденовая фольга толщиной $200 \mu \mathrm{m}$ была окислена при давлении кислорода 1 Torr и температуре $1000 \mathrm{~K}$ в течение $1 \mathrm{~h}$. Перед фотоэмиссионными измерениями окисленная молибденовая фольга была прикреплена к подложке из нержавеющей стали, с которой она была в омическом контакте. Фотоэмиссионные исследования были выполнены в Российско-Германской лаборатории на синхротроне HBZ BESSY II (Берлин, Германия) с использованием метода фотоэлектронной спектроскопии (ФЭС) при возбуждении в диапазоне энергий фотонов 80-600 eV. Регистрировались фотоэлектроны по нормали к поверхности, возбуждающий пучок падал на поверхность образца под углом $45^{\circ}$. До измерений образец был прогрет в сверхвысоком вакууме при температуре $\sim 900 \mathrm{~K}$. Исследования окисленной тонкой пленки молибдена и с напыленным натрием проводились in situ в вакууме $P<5 \cdot 10^{-10}$ Torr при комнатной температуре. Регистрировались спектры фотоэмиссии в области валентной зоны, а также спектры остовных уровней $\mathrm{O} 2 s$, $\mathrm{Mo} 3 d$, Мо $3 p$ и Na $2 p$. Полное энергетическое разрешение было $50 \mathrm{meV}$. Для всех приведенных ниже спектров 
фон был вычтен по методу Ширли. Атомарно-чистый $\mathrm{Na}$ напылялся на чистую поверхность образца из стандартного источника. Отметим, что за один монослой (ML) $\mathrm{Na}$ принимается концентрация $1.0 \cdot 10^{15} \mathrm{at} . / \mathrm{cm}^{2}$, при которой формируется укомплектованный слой атомов $\mathrm{Na}$. Покрытие атомов натрия определялось по ослаблению остовного пика $\mathrm{Fe} 3 s$ нержавеющей подложки, при энергии возбуждения фотоэмиссии $h v=600 \mathrm{eV}$ по известным значениям глубины выхода фотоэлектронов $\mathrm{Na}$ из работы [30].

\section{3. Экспериментальные результаты и обсуждение}

Нормированные спектры фотоэмиссии в области валентной зоны окисленного молибдена представлены на рис. 1 для энергий возбуждения в диапазоне от 80 до $600 \mathrm{eV}$. Спектры нормированы на максимальную интенсивность фотоэмиссии в валентной зоне для каждой энергии возбуждения и приведены к уровню Ферми $E_{F}$, который определялся линейной аппроксимацией низкоэнергетического края спектра валентной зоны подложки из нержавеющей стали. Для всех энергий возбуждения характерно наличие широкой валентной зоны окисла молибдена при энергиях связи 2.5-10 eV и двух максимумов вблизи уровня Ферми при энергиях

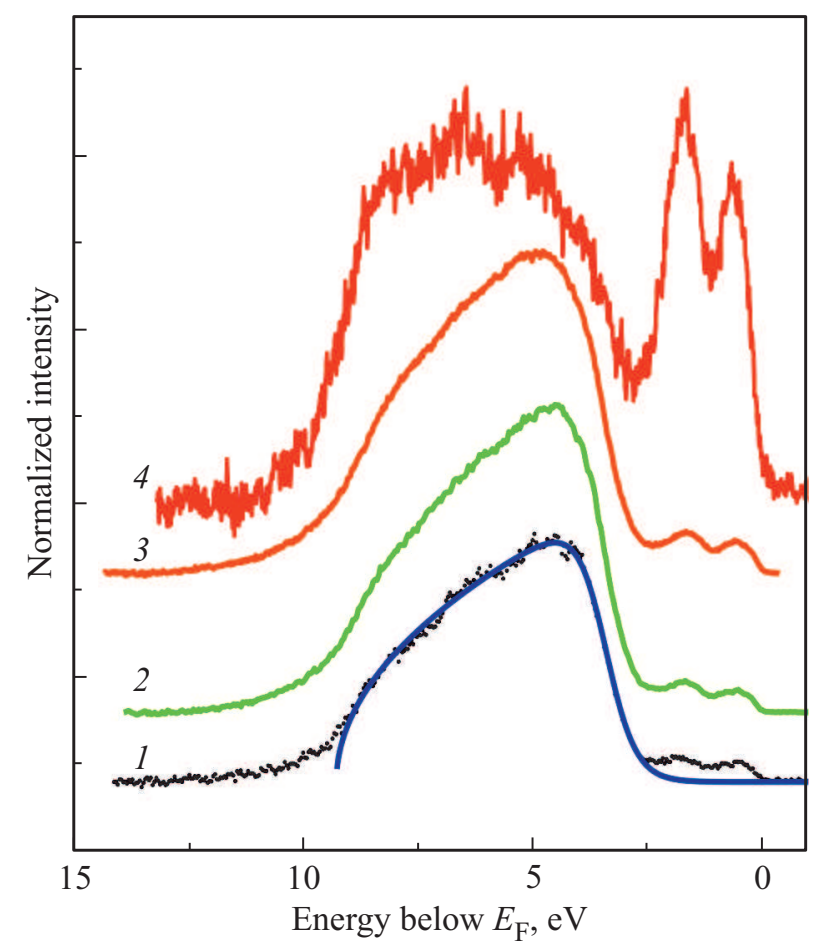

Pис. 1. Нормированные спектры фотоэмиссии в области валентной зоны для чистой поверхности окисленного молибдена при различных энергиях возбуждения $h v: 1-80 \mathrm{eV}$, $2-100 \mathrm{eV}, 3-120 \mathrm{eV}, 4-600 \mathrm{eV}$. Сплошной линией приведена аппроксимация валентной зоны окисла молибдена при энергии возбуждения $h v=80 \mathrm{eV}$. связи 0.5 и $1.6 \mathrm{eV}$, связаных с Мо $4 d$ состояниями (см., например, $[8,12])$. Форма спектра указывает на полупроводниковый характер окисла. Видно, что спектры валентной зоны при энергии возбуждения в диапазоне $h v=80-120 \mathrm{eV}$ близки друг к другу. Форма спектра в этой области очень напоминает распределение Ферми, что позволило провести аппроксимацию зарегистрированных спектров следующей функцией:

$$
g(E)=\sqrt{\frac{E_{0}-E}{E_{V B M}}}\left(\frac{a}{\exp \left(\frac{E_{0}-E-E_{V B M}}{k T}+1\right)}\right),
$$

где $a-$ нормировочный коэффициент, $E_{0}-$ сдвиг по энергии, $E_{V B M}$ - энергия уровня максимума валентной зоны относительно дна валентной зоны, $k$ - постоянная Больцмана, $T-$ температура. Слагаемое $E_{0}-E$ отражает тот факт, что уровень Ферми отсчитывается от дна валентной зоны, знак минус перед $E$ необходим для зеркального отображения спектров, приведенных на рис. 1. Также мы провели очевидную замену в $E_{F}$ на $E_{V B M}$, что кажется нам разумным, исходя из вида зарегистрированных спектров. Как видно из рис. 1, где приведена апроксимация зарегистрированного спектра при энергии возбуждения $h v=80 \mathrm{eV}$, модельная кривая хорошо согласуется с экспериментальной. В качестве подгоночных параметров использовались следующие величины: $E_{V B M}=5.8 \mathrm{eV}$ и $k T=0.31 \mathrm{eV}$. Большее значение $k T$ можно связать с приборным уширением линий, a расхождение между модельной и экспериментальной кривыми при энергиях связи больше $9.2 \mathrm{eV}$ очевидно объяснить разницей между идеализированным распределением и реальным энергетическим распределением электронной плотности для окисла молибдена на молибдене. Аналогичные значения были получены и для энергий возбуждения 100 и $120 \mathrm{eV}$. Для энергии возбуждения $h v=600 \mathrm{eV}$ спектр отличается от вышеописанных: существенно выше интенсивность для Мо $4 d$ состояний вблизи уровня Ферми, а также изменилась форма спектра валентной зоны, со сдвигом его максимума на $1.5 \mathrm{eV}$ в сторону больших энергий связи. Здесь следует отметить, что чем больше энергия возбуждения фотоэмиссии, тем с большей глубины образца происходит выход фотоэлектронов. Таким образом, при энергии возбуждения $h v=80 \mathrm{eV}$ происходит зондирование с минимальной глубины (около $1.5 \mathrm{~nm}$ ), т. е. поверхностная фотоэмиссия, а вот для энергии возбуждения $h v=600 \mathrm{eV}$ фотоэлектроны вылетают также и с более удаленных от поверхности слоев, т.е. в этом случае наблюдается объемная фотоэмиссия. Отметим также, что чем больше энергия возбуждения, тем больше интенсивность пика Мо 4d. Такие спектры могут указывать на то, что в приповерхностной области валентная зона сформирована в основном окислом $\mathrm{MoO}_{3}$ с небольшой примесью $\mathrm{MoO}_{2}$. А в глубине основным окислом является $\mathrm{MoO}_{2}$ с небольшой примесью $\mathrm{MoO}_{3}$. Это следует из логики процесса окисления, что чем дальше от поверхности, тем меньше атомов молибдена реагирует 
с кислородом и, следовательно, будет формироваться окисел с меньшей степенью окисления. На поверхности же логично ожидать формирование окисла с наибольшей степенью окисления. Форма спектра отличается от спектров окисла молибдена, полученного при окислении молибдена на воздухе, исследованного нами ранее [29]. Так, для окисла молибдена, окисленного на воздухе, не наблюдается Мо $4 d$ состояний вблизи уровня Ферми и сами спектры валентной зоны невозможно описать формулой (1). Спектр для энергии возбуждения $h v=600 \mathrm{eV}$ почти симметричны относительно максимума в спектре валентной зоны. Однако спектры валентной зоны при энергии возбуждения $h v=600 \mathrm{eV}$ совпадают в [29] и в настоящей работе, за исключением очевидной области вблизи уровня Ферми, где наблюдаются пики Мо $4 d$ состояний, что означает, что при окислении Мо на воздухе образуется окисел $\mathrm{MoO}_{3}$.

Исследованные спектры валентной зоны для энергий возбуждения $h v=80-120 \mathrm{eV}$ хорошо совпадают со спектрами валентной зоны различных окислов молибдена $[12,28,31,32]$. В [12] было показано, что по мере восстановления $\mathrm{MoO}_{3}$ до $\mathrm{MoO}_{2}$ происходит рост пиков Мо 4d состояний и незначительное изменение формы спектра валентной зоны в области энергий связи 3-10 eV. В [31] показано, что с увеличением температуры прогрева до $T=623 \mathrm{~K}$ вблизи уровня Ферми появляется пик, что свидетельствует о начале процесса восстановления состояний $\mathrm{Mo}^{6+}$. Полученный нами спектр валентной зоны и, в частности в области Мо $4 d$ состояний, при энергии возбуждения $h v=600 \mathrm{eV}$ совпадает с [8].

Нормированные спектры фотоэмиссии в области валентной зоны окисленного молибдена при дозе напыления $10 \mathrm{MLs}$ атомов $\mathrm{Na}$, представлены на рис. 2 для энергий возбуждения в диапазоне от 80 до $600 \mathrm{eV}$. Каждый спектр нормирован на максимальную интенсивность фотоэмиссии в валентной зоне для соответствующей энергии возбуждения для чистой поверхности окисла молибдена. Напыление атомов натрия не приводит к изменениям формы спектра валентной зоны. В то же время интенсивность в области валентной зоны уменьшается с ростом дозы напыленного натрия: в 2 раза для энергии возбуждения $h v=80 \mathrm{eV}$, на $12 \%$ для энергий возбуждения $h v=100$ и $120 \mathrm{eV}$ по сравнению с чистой поверхностью. Не найдено разницы в форме и интенсивности спектров валентной зоны при дозе напыления 5 и $10 \mathrm{MLs}$ атомов $\mathrm{Na}$ для энергий возбуждения $h v=80-120 \mathrm{eV}$. Для энергии возбуждения $h v=600 \mathrm{eV}$ спектр валентной зоны остается неизменным с напылением атомов натрия. Такое поведение свидетельствует об экранировке выхода фотоэлектронов из валентной зоны окисла молибдена в приповерхностной области, вызванной напылением атомов натрия. В случае же фотоэмиссии при энергии возбуждения $h v=600 \mathrm{eV}$ напыление атомов натрия не сказывается на общей интенсивности фотоэлектронов, так как вклад в фотоэмиссию вносит значительное число слоев подложки. Интенсивность Мо $4 d$ состояний остается неизменной вплоть до 5 MLs натрия, а затем, к $10 \mathrm{MLs}$, возрастает на треть. Увеличение пика Мо $4 d$ следует связать с восстановлением $\mathrm{Mo}^{6+}$ до $\mathrm{Mo}^{4+}$. Причины восстановления окисла и процессы, происходящие при напылении атомов натрия, будут рассмотрены ниже.

Известно, что адсорбция атомов натрия на поверхности $\mathrm{MoO}_{3}$ не приводит к изменениям в спектрах валентной зоны [29]. Похожие результаты были получены в [33], где была исследована адсорбция атомов калия на поверхность $\mathrm{MoO}_{3}$, и также не было обнаружено влияние адсорбции атомов калия на спектр валентной зоны. Однако заметные изменения в спектре валентной зоны наблюдались при электрохимической интеркаляции $\mathrm{MoO}_{3}$ атомами лития в [7].

На рис. 3 приведен спектр фотоэмиссии остовного уровня дублета Мо $3 d$ для чистой поверхности окисленного молибдена при энергии возбуждения $h v=280 \mathrm{eV}$. При данной энергии возбуждения фотоэмиссии достигается минимальная глубина выхода фотоэлектронов. В спектре видно 4 пика: 2 узких и 2 широких пика с максимумами при энергиях связи: $\sim 234,232.6 \mathrm{eV}$, $\sim 231$ и $229.4 \mathrm{eV}$. Расстояние между уровнями в дублете $-3.1 \mathrm{eV}$. Для металлического молибдена Мо $3 d_{5 / 2}$

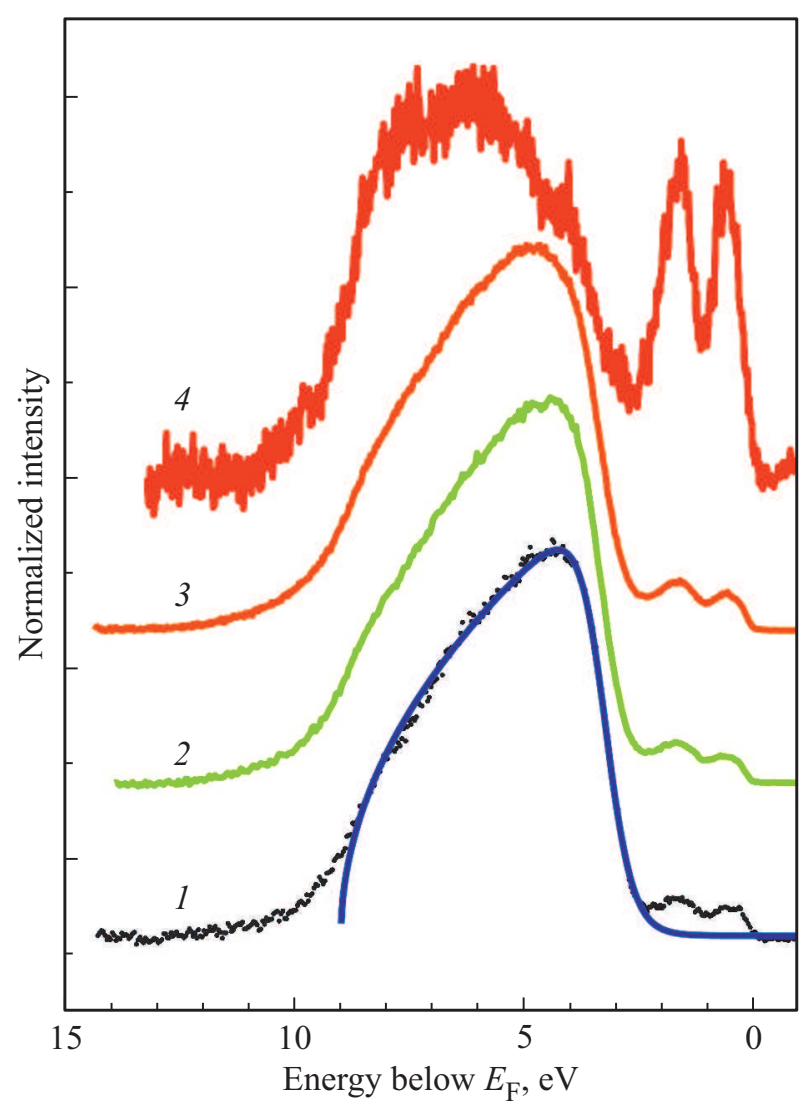

Рис. 2. Нормированные спектры фотоэмиссии в области валентной зоны для поверхности окисленного молибдена при дозе напыления $10 \mathrm{MLs}$ атомов Na при различных энергиях возбуждения $h v: 1-80 \mathrm{eV}, 2-100 \mathrm{eV}, 3-120 \mathrm{eV}$, $4-600 \mathrm{eV}$. Сплошной линией приведена аппроксимация валентной зоны при энергии возбуждения $h v=80 \mathrm{eV}$. 
пик находится при $228.0 \mathrm{eV}$ и в полученных спектрах не наблюдается. Если в поверхностных слоях были бы вкрапления металлического молибдена, тогда должен был наблюдаться металлический край зоны вблизи уровня Ферми, а не два небольших пика, которые приписываются состояниям Мo $4 d$, как это следует из теоретических и экспериментальных данных, например, $[8,12]$. Наблюдаемые пики логично связать с окислами молибдена со степенями окисления молибдена $4^{+}$и $6^{+}$с энергиями связи 229.5 и $231.2 \mathrm{eV}$ для уровня Мо $3 d_{3 / 2}$. Было проведено разложение экспериментального спектра парами функций Гаусса с спектральным расщеплением равным $3.1 \mathrm{eV}$ и соотношением интенсивностей $3: 2$. Результаты разложения также приведены на рис. 3. Параметры разложения, такие как: положение максимумов интенсивности - энергия связи $\left(E_{b}\right)$ относительно уровня Ферми, полная ширина на полувысоте пика $(\Gamma)$ и относительная площадь $(A)$ под пиком в процентах приведены в таблице. Как видно из анализа спектра, на поверхности присутствуют окислы $\mathrm{MoO}_{2}$ и $\mathrm{MoO}_{3}$ с преобладанием последнего. Ширина пика $\mathrm{Mo}^{4+}$ в несколько раз меньше, чем $\mathrm{Mo}^{6+}$, аналогичный результат был получен в [22] при восстановлении $\mathrm{Mo}^{6+}$ до $\mathrm{Mo}^{4+}$.

Анализ работ по термическому окислению пленок молибдена показывает, что при похожих на наши условиях окисления, может формироваться окисел $\mathrm{MoO}_{3}$, а наличие различных окислов объясняется, как восстановлением $\mathrm{Mo}^{6+}$, так и более низкой температурой окисления. В [25] исследовано окисление молибденовой фольги в кислороде при температуре $673 \mathrm{~K}$ в течение $1 \mathrm{~h}$, которое приводит к формированию аморфной пленки окисла $\mathrm{MoO}_{3}$ толщиной более $11 \mathrm{~nm}$ без дополнительных примесей. Преобладание двух окислов

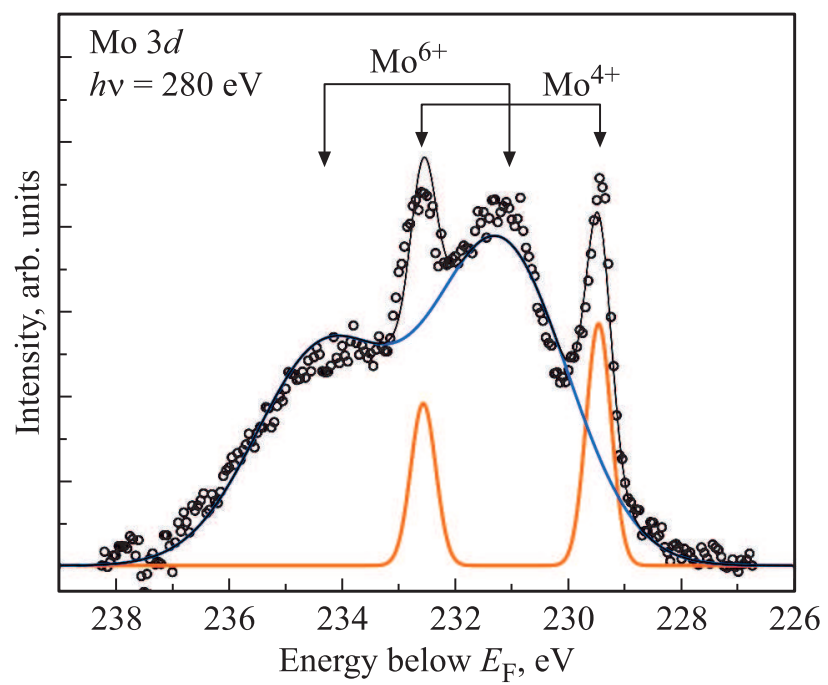

Pис. 3. Анализ спектра фотоэмиссии остовного уровня Мо $3 d$ для чистой поверхности окисленного молибдена при энергии возбуждения $h v=280 \mathrm{eV}$. Точками приведен экспериментальный спектр, толстыми сплошными линиями приведен вклад $\mathrm{Mo}^{6+}$ - и $\mathrm{Mo}^{4+}$-состояний, сплошной тонкой линией приведена общая сумма пиков.

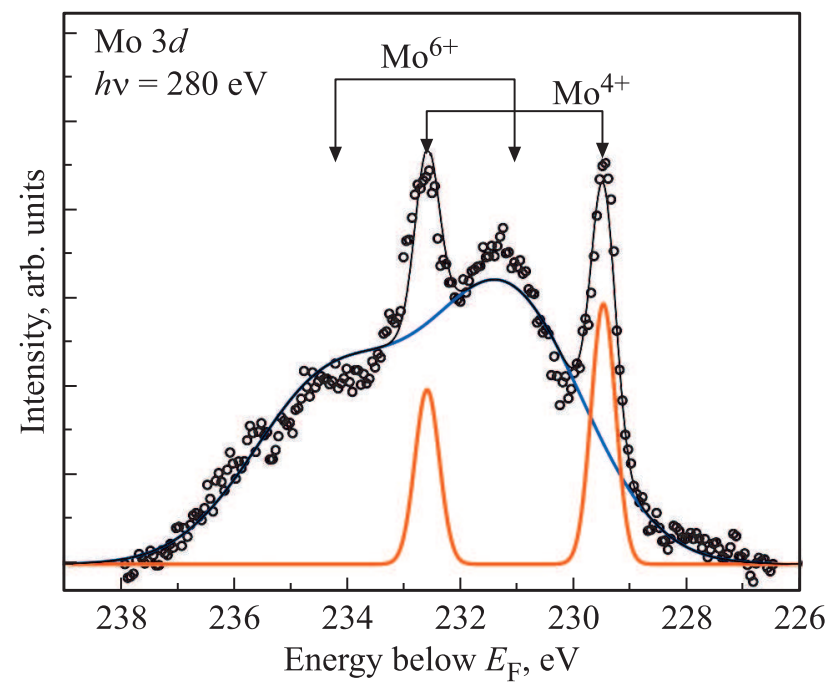

Рис. 4. Анализ нормированного спектра фотоэмиссии остовного уровня Мо $3 d$ для поверхности окисленного молибдена при дозе напыления $10 \mathrm{MLs}$ атомов $\mathrm{Na}$ при энергии возбуждения $h v=280 \mathrm{eV}$. Точками приведен экспериментальный спектр, толстыми сплошными линиями приведен вклад $\mathrm{Mo}^{6+}$. и $\mathrm{Mo}^{4+}$-состояний, тонкой сплошной линией приведена общая сумма пиков.

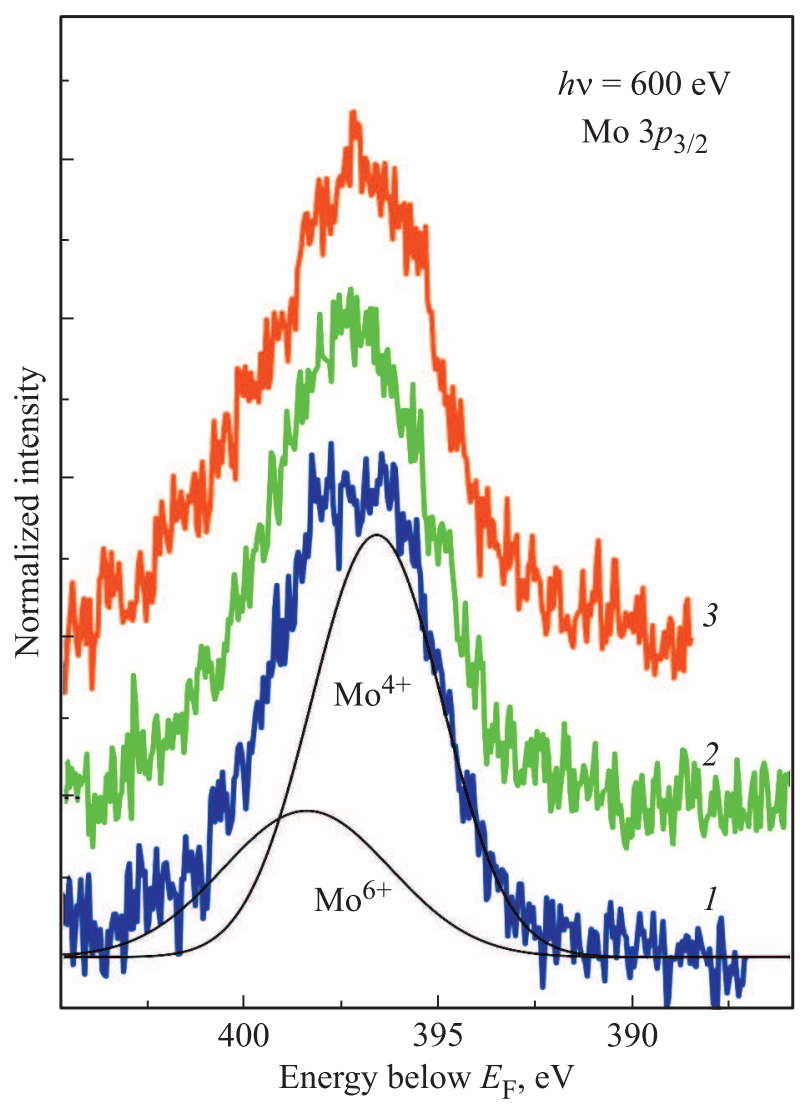

Рис. 5. Нормированные спектры фотоэмиссии остовного уровня Мо $3 p_{3 / 2}$ для чистой поверхности окисленного молибдена (1), при дозе напыления $5 \mathrm{MLs}$ атомов $\mathrm{Na}(2)$, при дозе напыления $10 \mathrm{MLs}$ атомов $\mathrm{Na}(3)$. Энергия возбуждения $h v=600 \mathrm{eV}$. 


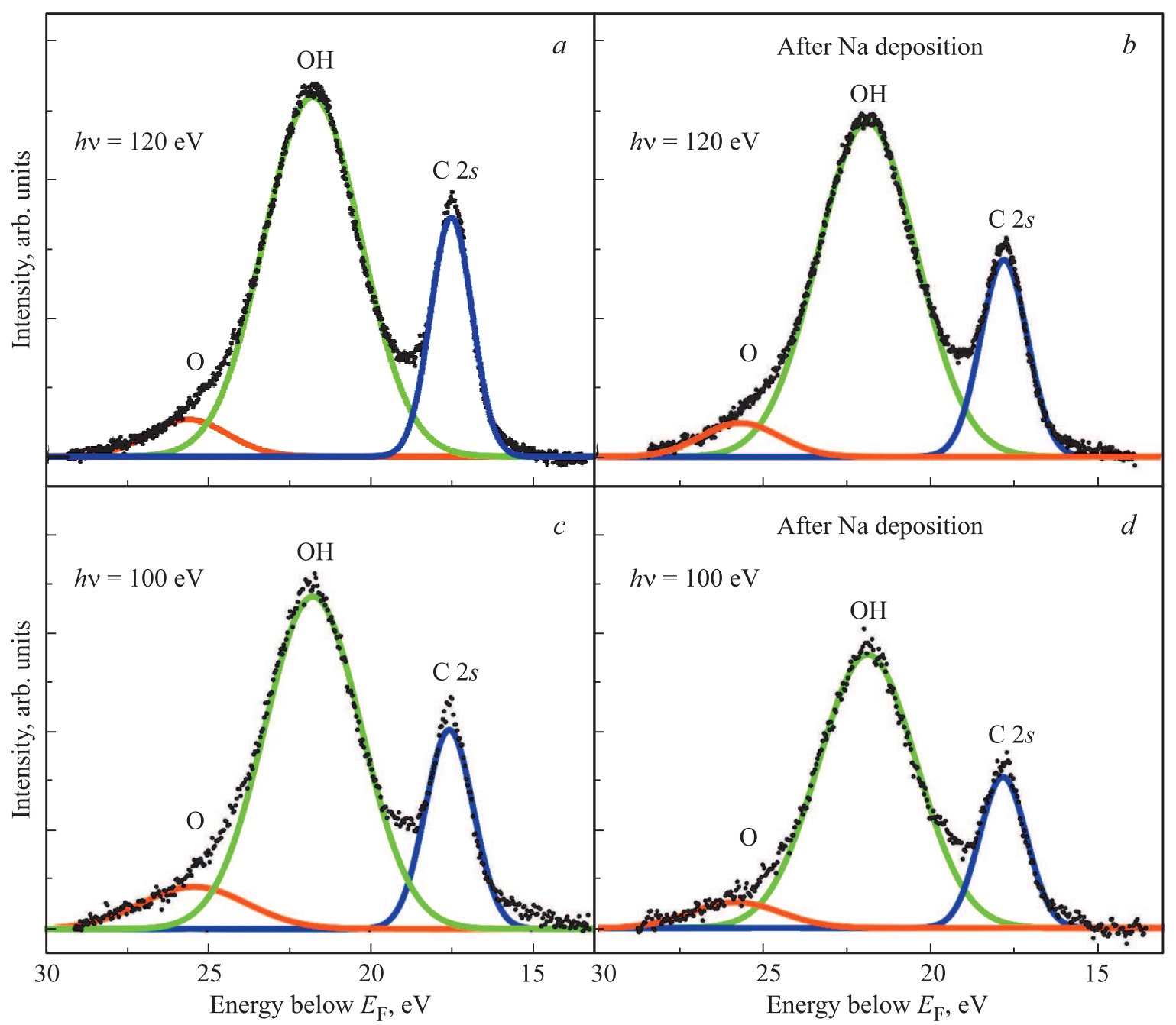

Рис. 6. Спектры фотоэмиссии остовных уровней $\mathrm{O} 2 s$ и $\mathrm{C} 2 s$ для чистой поверхности окисленного молибдена $(a$ и $c)$ и для поверхности окисленного молибдена при дозе напыления $5 \mathrm{MLs}$ атомов $\mathrm{Na}(b$ и $d)$ для энергий возбуждения $h v=100 \mathrm{eV}$ и $h v=120 \mathrm{eV}$. Точки - экспериментальные данные, сплошными линиями приведены аппроксимации спектров остовных уровней $\mathrm{O} 2 s$ и С $2 s$ функциями Гаусса.

$\mathrm{MoO}_{2}$ и $\mathrm{MoO}_{3}$ с небольшой примесью $\mathrm{Mo}_{2} \mathrm{O}_{5}$ в пленках окислов, полученных не при термическом окислении, наблюдалось, например, в [34,35].

После напыления дозы в 10 MLs атомов Na форма спектра фотоэмиссии остовного уровня Мо $3 d$ при энер-

Энергия связи уровней Мо $3 d_{5 / 2}\left(E_{b}\right)$, ширина пика на полувысоте $(\Gamma)$ и относительная площадь $(A A)$, занимаемая пиком для чистой поверхности молибдена и при дозе напыления $10 \mathrm{MLs}$ атомов $\mathrm{Na}$.

\begin{tabular}{l|c|c|c|c}
\hline & $\mathrm{Mo}^{4+}$ & $\mathrm{Mo}^{4+}$ & $\mathrm{Mo}^{6+}$ & $\mathrm{Mo}^{6+}$ \\
\hline & До & После & До & После \\
& $\begin{array}{c}\text { напыления } \\
\mathrm{Na}\end{array}$ & $\begin{array}{c}\text { напыления } \\
\mathrm{Na}\end{array}$ & $\begin{array}{c}\text { напыления } \\
\mathrm{Na}\end{array}$ & $\begin{array}{c}\text { напыления } \\
\mathrm{Na}\end{array}$ \\
\hline$E_{b}, \mathrm{eV}$ & 229.5 & 229.5 & 231.2 & 231.2 \\
$\Gamma, \mathrm{eV}$ & 0.5 & 0.51 & 2.8 & 3.2 \\
$A, \%$ & 12 & 13 & 88 & 87
\end{tabular}

гии возбуждения $h v=280 \mathrm{eV}$ качественно не поменялась. Экспериментальные результаты, а также разложение экспериментального спектра парами функций Гаусса со спектральным расщеплением равным $3.1 \mathrm{eV}$ и соотношением интенсивностей $3: 2$ приведено на рис. 4. Результаты анализа разложения спектра Mo $3 d$ на составляющие приведены в таблице. Ширина линий увеличилась незначительно, и также незначительно изменилась доля площадей для разных окислов. Этот результат показывает, что напыление атомов натрия на окисленный молибден не приводит к изменению спектра Мо $3 d$, что может означать слабое взаимодействие атомов натрия с поверхностью окисла молибдена. Это возможно в случае интеркаляции атомов натрия в решетку окисла $\mathrm{MoO}_{3}$ с расположением атомов натрия между слоев октаэдров $\mathrm{MoO}_{6}$, связанных между собой силами Ван-дер-Ваальса и образующих элементарную ячейку $\mathrm{MoO}_{3}$.

Наши результаты коррелируют с работой [6], где исследовано изменение спектра уровня Мо $3 d$ окисла 


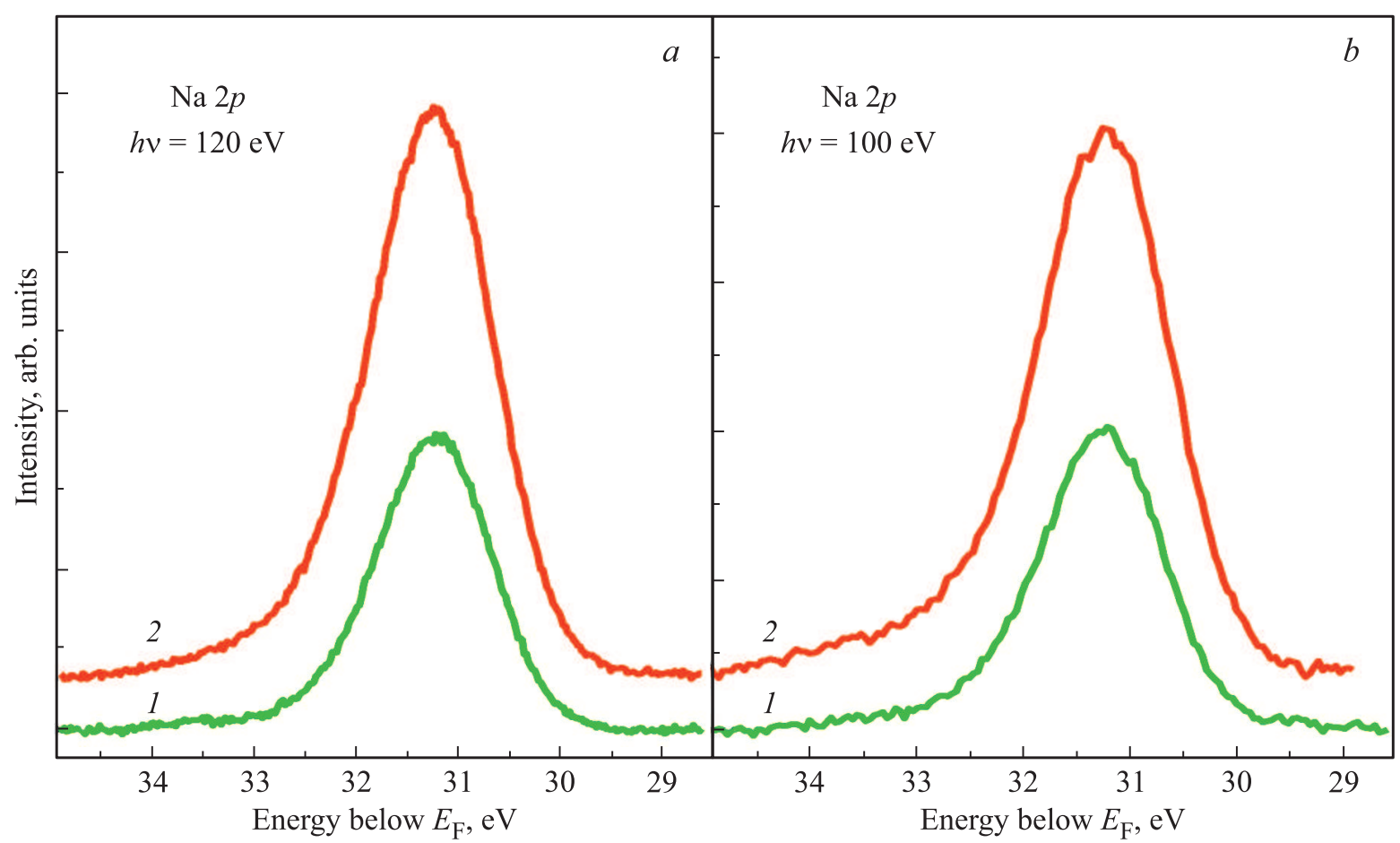

Рис. 7. Спектры фотоэмиссии остовных уровней $\mathrm{Na} 2 p$ для поверхности окисленного молибдена: 1 - при дозе напыления $5 \mathrm{MLs}$ атомов Na, 2 - при дозе напыления $10 \mathrm{MLs}$ атомов Na при энергиях возбуждения $h v=120 \mathrm{eV}(a)$ и $100 \mathrm{eV}(b)$.

$\mathrm{MoO}_{3}$ от концентрации калия в соединении $\mathrm{K}_{x} \mathrm{MoO}_{3}$ и показано, что увеличение доли калия до $x=0.075$ приводит к появлению в спектре Мо $3 d$-пиков, соответствующих $\mathrm{Mo}^{5+}$ и $\mathrm{Mo}^{4+}$, что указывает на восстановление $\mathrm{Mo}^{6+}$. Восстановление $\mathrm{Mo}^{6+}$ до $\mathrm{Mo}^{5+}$ и $\mathrm{Mo}^{4+}$ при электрохимической интеркаляции $\mathrm{MoO}_{3}$ атомами лития наблюдались в [7], в которой найдено увеличение до двух раз ширины компонентов спектра уровня Мо $3 d$, соответствующих различным степеням окисления молибдена.

На рис. 5 приведены спектры фотоэмиссии остовного уровня Мо $3 p_{3 / 2}$ при энергии возбуждения $h v=600 \mathrm{eV}$, c большей кинетической энергией фотоэлектронов, чем при энергии возбуждения $h v=280 \mathrm{eV}$ и, соответственно, с большей глубиной зондирования. Спектр уровня Мо $3 p_{1 / 2}$ не приведен, так как на него наложен Оже-пик $M N V$. Для чистой поверхности окисленного молибдена наблюдается широкий без особенностей пик, ширина которого в 1.6 раза больше, чем пика Мо $3 d_{5 / 2}$. Отсутствие видимых особенностей в пике Мо $3 p_{3 / 2}$ не позволяет провести корректного анализа, как и для пика Mo $3 d_{5 / 2}$, однако, как следует из экспериментальных данных приведенных выше, логично пик Мо $3 p_{3 / 2}$ разложить на два, соответствующие состояниям $\mathrm{Mo}^{4+}$ и $\mathrm{Mo}^{6+}$. Доля площади пика, соответствующая окислу $\mathrm{MoO}_{2}$ возрастает до $70 \%$. Увеличение доли $\mathrm{MoO}_{2}$ свидетельствует об уменьшении концентрации кислорода в процессе окисления с увеличением расстояния от поверхности. Данный результат коррелирует с изменением формы спектра валентной зоны от энергии возбуждения. Напыление натрия на окисел молибдена не оказывает заметного влияния ни на интенсивность фотоэмиссии, ни на форму спектра пика Мо $3 p_{3 / 2}$.

Спектры фотоэмиссии остовных уровней О $2 s$ и С $2 s$ для чистой поверхности окисленного молибдена приведены на рис. 6, $a$ и $c$ для двух энергий возбуждения $h v=120$ и $h v=100 \mathrm{eV}$ соответственно. Кроме широкого пика остовного уровня О $2 s$ в спектре виден пик остовного уровня C $2 s$. Пик углерода связан с поверхностными загрязнениями. Стоит здесь отметить, что пик $\mathrm{C} 1 s$ при энергии возбуждения $h v=600 \mathrm{eV}$ лишь слегка превышает фон. Анализ пика O $2 s$ позволяет разделить его на два пика с энергиями связи 21.7 и $25.5 \mathrm{eV}$, соответствующая аппроксимация функциями Гаусса приведена на рис. 5. Как и в [29], эти пики приписаны гидроксилу $\mathrm{OH}^{-}$при энергии связи $21.7 \mathrm{eV}$ и состоянию кислорода $\mathrm{O}^{2-}$ при энергии связи $25.5 \mathrm{eV}$. Полная ширина пиков на полувысоте при энергии возбуждения $h v=100 \mathrm{eV}$ равна 1.91 и $1.75 \mathrm{eV}$ для гидроксила и кислорода соответственно. Для энергии возбуждения $h v=120 \mathrm{eV}$ ширина пика кислорода в составе гидроксила меньше на $0.55 \mathrm{eV}$ по сравнению с энергией возбуждения $h v=100 \mathrm{eV}$.

Напыление 5 MLs атомов натрия приводит к изменению остовных уровней О $2 s$ и С $2 s$, спектры которых для двух энергий возбуждения $h v=120 \mathrm{eV}$ и $h v=100 \mathrm{eV}$ приведены на рис. $6, b$ и $d$ соответственно. Как видно, происходит уменьшение интенсивности линий при сохранении неизменной ширины пиков. Площадь пика кислорода в составе окислов молибдена для энергии возбуждения $h v=100 \mathrm{eV}$ после адсорбции натрия уменьшается в 2 раза, что в несколько раз больше, чем для 
энергии возбуждения $h v=120 \mathrm{eV}$, что может указывать на предпочтительную адсорбцию атомов натрия на кислороде в составе окислов, а не на реакцию с гидроксилом [29]. Спектры при напылении 5 и $10 \mathrm{MLs}$ натрия идентичны, что указывает на диффузию атомов натрия вглубь окисла, т.е. на интеркаляцию. При этом стоит отметить, что если определять покрытие по подавлению пиков О $2 s$ и С $2 s$, то получится, что на поверхности адсорбировано всего $0.5 \mathrm{ML}$ атомов натрия, что указывает на диффузию основного количества напыленного натрия в окисел молибдена.

В качестве дополнительного подтверждения рассмотрим спектры фотоэмиссии остовных уровней $\mathrm{Na} 2 p$, приведенные на рис. 7 для доз напыления 5 и $10 \mathrm{MLs}$ атомов $\mathrm{Na}$, для двух энергией возбуждения $h v=100 \mathrm{eV}$ и $h v=120 \mathrm{eV}$. Ширина пика на полувысоте составляет $1.42 \mathrm{eV}$. Площадь под пиком Na $2 p$ для энергии возбуждения $h v=100 \mathrm{eV}$ возрастает в 1.90 раза и в 1.94 раза для энергии возбуждения $h v=120 \mathrm{eV}$ при неизменности пиков О $2 s$ и С $2 s$. Это прямо указ ывает на диффузию атомов натрия в приповерхностную область окисла.

\section{4. Заключение}

Анализ экспериментальных данных спектров валентной зоны и остовных состояний (Мо $3 d$, Мо $3 p_{3 / 2}$, О $2 s$ и $\mathrm{Na} 2 p$ ) для чистой поверхности окисла молибдена, полученного при термическом окислении молибденовой фольги, и после напыления на нее атомов натрия позволяет сделать следующие выводы. На поверхности и ближайших к поверхности слоях образуется окисел $\mathrm{MoO}_{3}$ с небольшой примесью окисла $\mathrm{MoO}_{2}$, что находит отражение в спектре валентной зоны с небольшим вкладом Мо $4 d$ состояний вблизи уровня Ферми. В спектре остовных состояний также преобладает вклад $\mathrm{Mo}^{6+}$-состояний с небольшой долей примеси $\mathrm{Mo}^{4+}$-состояний. Кислород на поверхности находится в двух состояниях: в составе окисла и гидроксила. С увеличением расстояния от поверхности доля $\mathrm{Mo}^{4+}$ состояний возрастает, что следует из спектров Мо $3 d$ и Мо $3 p_{3 / 2}$-состояний. Это может быть вызвано двумя причинами: во-первых, частичным восстановлением $\mathrm{Mo}^{6+}$ до $\mathrm{Mo}^{4+}$ в процессе прогрева образца перед исследованиями и, во-вторых, дефицитом кислорода в процессе формирования окисла. Дальнейшее увеличение расстояния от поверхности приводит к регистрации уже спектров валентной зоны, соответствующей $\mathrm{MoO}_{2}$.

Напыление большой дозы атомов натрия (5-10 MLs) приводит к тому, что на поверхности формируется небольшое покрытие атомов натрия $\sim 0.5 \mathrm{ML}$, а остальной натрий диффундирует в слой окисла, т. е. происходит интеркаляция атомами натрия окисленной пленки. Разное изменение интенсивности спектра валентной зоны для энергий возбуждения $h v=80-120 \mathrm{eV}$ можно объяснить тем, что количество интеркалированного натрия также уменьшается с удалением от поверхности. Рост
Мо $4 d$ состояний вблизи уровня Ферми в глубине образца может свидетельствовать о дополнительном восстановлении до $\mathrm{Mo}^{4+}$. Удивительным фактом является то, что не произошло изменений спектров валентной зоны после напыления натрия, что свидетельствует о слабом взаимодействии атомов натрия с окислом молибдена в пленке и является дополнительным доказательством интеркаляции натрием окисла молибдена.

\section{Финансирование работы}

Исследование выполнено при финансовой поддержке РФФИ в рамках научного проекта № 20-02-00370. Этот исследовательский проект был поддержан РоссийскоГерманской лабораторией на BESSY II. Мы благодарим HZB за выделение времени пучка синхротронного излучения.

\section{Конфликт интересов}

Авторы заявляют, что у них нет конфликта интересов.

\section{Список литературы}

[1] H. Liu, X. Liu, S. Wang, H.-K. Liu b, L. Li. Energy Storage Mater. 28, 122 (2020).

[2] J. Warner. Lithium-Ion Battery Chemistries. Elsevier (2019). $353 \mathrm{p}$.

[3] P. Zhang, S. Guo, J. Liu, C. Zhou, S. Li, Y. Yang, J. Wu, D. Yu, L. Chen. J. Colloid Interface Sci. 563, 318 (2020).

[4] Y. Dong, X. Xu, S. Li, C. Han, K. Zhao, L. Zhang, C. Niu, Z. Huang, L. Mai. Nano Energy 15, 145 (2015).

[5] S. Li, H. Hou, Z. Huang, H. Liao, X. Qiu, X. Ji. Electrochim. Acta 245, 949 (2017).

[6] Z. Hu, X. Zhang, C. Peng, G. Lei, Z. Li. J. Alloys Comp. 826, 154055 (2020).

[7] J. Światowska-Mrowiecka, S. de Diesbach, V. Maurice, S. Zanna, L. Klein, E. Briand, I. Vickridge, P. Marcus. J. Phys. Chem. C 112, 11050 (2000).

[8] D.O. Scanlon, G.W. Watson, D.J. Payne, G.R. Atkinson, R.G. Egdell, D.S.L. Law. J. Phys. Chem. C 114, 4636 (2010).

[9] W. Xia, F. Xu, C. Zhu, H.L. Xin, Q. Xu, P. Sun, L. Sun. Nano Energy 27, 447 (2016).

[10] A.D. Sayede, T. Amriou, M. Pernisek, B. Khelifa, C. Mathieu. Chem. Phys. 316, 72 (2005).

[11] R. Tokarz-Sobieraj, K. Hermann, M. Witko, G. Mestl, R. Schlögl. Surf. Sci. 489, 107(2001).

[12] Q. Qu, W.B. Zhang, K. Huang, H.M. Chen. Comput. Mater. Sci. 130, 242 (2017).

[13] Y.Zh. Wang, M. Yang, D.C. Qi, S. Chen, W. Chen, A.T.S. Wee, X.Y. Gao. J. Chem. Phys. 134, 034706 (2011).

[14] A.Borgschulte, O. Sambalova, R. Delmelle, S. Jenatsch, R. Hany, F. Nüesch. Sci. Rep. 7, 40761(2017).

[15] P.C. Kao, Z.H. Chen, H.E. Yen, T.H. Liu, C.L. Huang. Jpn. J. Appl. Phys. 57, 03 DA04 (2018).

[16] A.T. Martí-Luengo, H. Köstenbauer, J. Winkler, A. Bonanni. AIP Adv. 7, 015034 (2017).

[17] H.-S. Kim, J.B. Cook, S.H. Tolbert, B. Dunn. J. Electrochem. Soc. 162, A5083 (2015). 
[18] J. Baltrusaitis, B. Mendoza-Sanchez, V. Fernandez, R. Veenstra, N. Dukstiene, A. Roberts, N. Fairley. Appl. Surf. Sci. 326, 151 (2015).

[19] O. Mohamed, J. Kappertz, T. Ngaruiya, L. Pedersen, R. Drese, M. Wuttig. Thin Solid Films 429, 135 (2003).

[20] S.T. Nishanthi, A. Baruah, K.K. Yadav, D. Sarker, S.G.A.K. Ganguli, M. Jha. Appl. Surf. Sci. 467-468, 1148 (2019).

[21] A. de Castro, R.S. Datta, J.Z. Ou, S. Sriram, T. Daeneke, K. Kalantar-zadeh. Adv. Mater. 29, 1701619 (2017).

[22] P.A. Spevack, N.S. McIntyre. J. Phys. Chem. 96, 9029 (1992).

[23] V. Madhavi, P. Kondaiah, S.S. Rayudu, O.M. Hussain, S. Uthanna. Mater. Exp. 3, 135 (2013).

[24] N.S. McIntyre, D.D. Jobnston, L.L. Coatswortb, R.D. Davidson. Surf. Interface Anal. 15, 265 (1990).

[25] R. Chalamala, R.H. Reuss, Y. Wei, J.M. Bernhard, E.D. Sosa, D.E. Golden, S. Aggarwal, R. Ramesh. Mat. Res. Soc. Symp. Proc. 685E, D14.2.1 (2001).

[26] A. Galtyaries, S. Wisniewski, J. Grimblot. J. Electron Spectr. Rel. Phenom. 87, 31 (1997).

[27] J. Badovinac, I.K. Piltaver, I. Sarlic, R. Peter, M. Petravic. Mater.Technol. 51, 617 (2017).

[28] P. Reddy, N.B. Mhamane, M.K. Ghosalya, C.S. Gopinath. J. Phys. Chem. C 122, 23034 (2018).

[29] П.А. Дементьев, Е.В. Иванова, М.Н. Лапушкин, Д.А. Смирнов, С.Н. Тимошнев. ФТТ 61, 2024 (2019).

[30] S. Tanuma, C.J. Powell, D.R. Penn. Surf. Interf. Anal. 21, 165 (1994).

[31] A. Siokou, G. Leftheriotis, S. Ppapaefthimiou, P. Yianoulis. Surf. Sci. 482-485, 294 (2001).

[32] K. Inzani, M. Nematollahi, F. Vullum-Bruer, T. Grande, T.W. Reenaas, S.M. Selbach. Phys. Chem. Chem. Phys. 19, 9232 (2017).

[33] M. Sing, R. Neudert, H. von Lips, M.S. Golden, M. Knupfer, J. Fink, R. Claessen, J. Muecke, H. Schmitt, S. Huefner, B. Lommel, W. Aßmus, Ch. Jung, C. Hellwig. Phys. Rev. B 60, 8559 (1999).

[34] A. Katrib, J.W. Sobczak, M. Krawczyk, L. Zommer, A. Benadda, A. Jablonski, G. Maire. Surf. Interface Anal. 34, 225 (2002).

[35] R.K. Sahoo. Catalytic Synthesis of Higher Alcohols from Syngas, PhD Thesis. Lehigh University, Bethlehem (2015). $295 \mathrm{p}$.

Редактор К.В. Емцев 